\title{
BAHASA SEBAGAI NILAI PEREKAT DALAM SIMBOL BUDAYA LOKAL TOKOH AGAMA
}

\author{
Abubakar ${ }^{1}$, Ngalimun $^{2}$, Fimier Liadi ${ }^{3}$, Latifah $^{4}$ \\ IAIN Palangka Raya ${ }^{1,3}$, Akademi Pariwisatan Nasional Banjarmasin ${ }^{2,4}$ \\ ngalimun@akparnas.ac.id
}

\begin{abstract}
This research is a field research by emphasizing the method of observation and in-depth interviews with deliberately selected research subjects. Research subjects deemed relevant in this study were religious leaders, cultural leaders, intellectual and academic figures and government official figures. In general, the value of adhesive in local cultural symbols Religious Leaders in Palangka Raya is a pattern of interaction "integrative solidarity", it is marked by some adhesive values in local cultural symbols in Palangka Raya, namely: Belom Bahadat values, cultural values that always uphold custom. have a sense of togetherness in building solidarity, openness and sincerity in serving guests as a form of plural society, then respecting the unity and unity and differences of each religion, because differences are sunnatullah and inevitability that cannot be ignored. The spirit of mutual cooperation, deliberation and equality as a form of betang huma culture which became the culture of the Dayak community. Adil Ka'talino, which values justice and truth, builds harmony, harmony and balance as a hereditary tradition that has been passed down from previous generations. The value of the Simpang Penyang Simpei, which is to live in peace and prosperity as an implementation of the harmonization of Dayak culture. The value of Pancasila spirituality, as the glue of national spirit, is based on local cultural wisdom and the integrative power of the Pancasila national culture, so Palangka Raya in Central Kalimantan is known for its motto, "Bumi Tambun Bungai Bumi Pancasila, Bhinneka Tungggal Ika."
\end{abstract}

Keywords: adhesive values, cultural symbols, religious leaders

lnteraksi sosial tidak dapat dibatasi dalam konteks masyarakat tertentu, karena merupakan fenomena yang bersifat universal. Apapun jenis masyarakatnya interaksi sosial telah dihadapi oleh setiap individu dan masyarakat ${ }^{1}$. Jika terjadi perbedaan hanya terletak pada hal interaksi, bentuk-bentuk serta dalam konteks apa terjadinya interaksi sosial. Contoh pola interaksi sosial antara kelompok sosial

\footnotetext{
${ }^{1}$ Ngalimun dan Makmur Harun (2020) Bahasa dan Komunikasi Perspektif Budaya. Yoyakarta: KMedia. Hal 17 
peguyuban (gemeinscnaft) dengan kelompok sosial petembayan (gesellschaft) ${ }^{2}$. Begitu juga halnya seseorang merasa termasuk anggota suatu kelompok apabila berpartisipasi dalam kegiatan dan tingkah laku kelompok, kesadaran akan keanggotaannya itu tergantung dari intensitas keterlibatannya dalam kegiatan itu. Sebab semakin tinggi tingkat keterlibatan seseorang dalam kegiatan kelompok, maka semakin dalam pula rasa kesatuan (kohesinya) dengan kelompok di mana ia menjadi anggotanya ${ }^{3}$. Dalam kelompok paguyuban kehidupan bersama anggotaanggotanya diikat oleh hubungan batin murni dan bersifat alamiah dan kekal ${ }^{4}$. Dalam hubungan tersebut adalah rasa cinta dan rasa kesatuan batin yang dikodratkan. Sedangkan dalam kelompok petembayan merupakan ikatan lahir yang bersifat pokok untuk jangka waktu tertentu yang pendek bersifat pikiran belaka (imaginary) serta strukturnya bersifat mekanis ${ }^{5}$.

Terlepas dari adanya perbedaan antara kedua kelompok masyarakat tersebut di atas, interaksi sosial merupakan proses sosial yang tidak mungkin dihindari karena merupakan kebutuhan manusia, sehingga harus ditumbuhkembangkan menjadi suatu kekuatan interaksi, baik dalam skala makro maupun mikro guna mewujudkan harmoni sosial (social harmony) dan menciptakan tertib sosial (social order) ${ }^{6}$.

Dari uraian di atas, ternyata ada persoalan yang sangat menarik untuk dikaji yaitu agama dipandang sebagai salah satu faktor interaksi sosial, yaitu sebagai pembentuk jarak sosial obyektif yang mempengaruhi pola interaksional dalam masyarakat. Jika dikaji dari kerangka berpikir "pluralisme agama", adalah sangat memungkinkan agama membentuk "ruang sosial" dari masing-masing jenis dan pemeluk agama yang pada akhirnya akan mempengaruhi pola interaksi sosial

${ }^{2}$ Tonnies Ferdinan dalam soerjono Soekanto (1997), Sosiolog. Jakarta: Raja Grafindo Persada. Hal 144. Kemudian bandingkan engan GW Allport dalam D Hendropuspito, O.C. (1994), Sosiologi Agama. Jakarta: Kanisius. Hal 93

3 .Ngalimun (2018) Komunikasi Antarbudaya. Yoyakarta: Pustaka Pelajar. Hal 26

${ }^{4}$ Abubakar HM, dkk (2018) Elit Agama Dan Harmonisasi Sosial Di Palangka Raya. Jurnal Khazanah: Jurnal Studi Islam dan Humaniora Vol 16 No 2

${ }^{5}$ Syamsul Arifin (1996) Spritual dalam Peradaban Massa. Yogyakarta: Sipee. Hal 4

${ }^{6}$ Syamsul Arifin (1996) Agama Konflik dan Interaksi Sosial. Yogyakarta: Pengalaman dari Desa Mojorejo (Laporan Penelitian S2). Hal 5 
di antara anggota masyarakat. Dalam kehidupan sosial yang pluralisme agamanya sangat menonjol, agama selalu tampil dalam keragaman bentuk ${ }^{7}$.

\section{METODE}

Penelitian ini merupakan penelitian lapangan dengan menekankan metode observasi dan wawancara mendalam dengan subyek penelitian yang dipilih secara sengaja (purposive). Subyek penelitian yang dianggap relevan dalam penelitian ini adalah:

Pertama, Para Tokoh Agama Islam, Kristen Protestan, Katholik, Hindu dan Budha dari subyek ini diharapkan memperoleh data tentang proses interaksi sosial antara Elit Agama;

Kedua, Para Tokoh Budaya yang memahami persoalan Budaya Dayak hubungannya dengan interaksi sosial dengan Tokoh agama di Kota Palangka Raya;

Ketiga, Tokoh Intelektual dan akademisi yang beragama Islam, Kristen Protestan, Katholik, Hindu dan Budha. Dari subyek ini diperoleh data tentang: Bagaimana pengaruh budaya, ekonomi dan persoalan sosial lainnya hubungannya dengan interaksi sosial antara Tokoh Agama di Palangka Raya;

Keempat, Tokoh Pejabat Pemerintah: Dan subyek ini diperoleh data tentang pandangan subyek terhadap pembinaan kerukunan hidup umat beragama Islam, Kristen Protestan Katholik, Hindu dan Buddha.

Sedangkan untuk melengkapi data jika diperlukan dapat digunakan responden yang disesuaikan dengan keperluan data di lapangan untuk menjaga jangan sampai data yang diperoleh belum memenuhi harapan dan kenyataan di lapangan, dengan demikian diperlukan penggalian data dari sumber lain walaupun bukan sebagai sumber utama, namun sangat berarti untuk memberikan informasi terhadap persoalan-persoalan yang diteliti, terutama yang berkaitan dengan masalah interaksi sosial. Di samping penelitian ini menggunakan metode dokumenter untuk mendapatkan data yang berhubungan dengan keadaan lokasi penelitian.

\footnotetext{
${ }^{7}$ Haeder Naser (1997) Agama dan Krisis Manusia Modern. Yogyakarta: Pustaka Pelajar. Hal 96 


\section{PEMBAHASAN}

\section{Memahami Interaksi Melalui Simbol Budaya Lokal}

Memaknai keberagamaan umat melalui simbol-simbol dalam interaksi sosial merupakan syarat yang diperlukan untuk menerjemahkan simbol tersebut sebagai media interaksi, sehingga makna simbol interaksi itu menjadi jelas, baik simbol bahasa, budaya Betang dan Rumah Ibadah $^{8}$. Hal ini menjadi substansi kajian pada bagian ini. Untuk memperjelas bagaimana memaknai keberagamaan umat melalui interaksi tokoh agama, maka perlu dijelaskan terlebih dahulu berbagai fungsi simbol yang digunakan dalam membangun interaksi, sebagaimana dikemukakan oleh Goodman sebagai berikut: ${ }^{9}$

Pertama, simbol memungkinkan orang menghadapi dunia material dan menggolongkan dan mengingat objek yang mereka jumpai di situ. Dengan cara ini manusia mampu menata kehidupan, agar tak membingungkan. Bahasa memungkinkan orang mengatakan, menggolongkan, dan terutama mengingat secara lebih efisien ketimbang yang dapat mereka lakukan dengan menggunakan jenis simbol lain seperti kesan bergambar.

Kedua, simbol meningkatkan kemampuan manusia untuk memahami lingkungan. Daripada dibanjiri oleh banyak stimulti yang tidak dapat dibedabedakan, aktor dapat berjaga-jaga terhadap bagian lingkungan tertentu saja ketimbang terhadap bagian lingkungan yang lain.

Ketiga, simbol meningkatkan kemampuan untuk berpikir. Jika sekumpulan simbol bergambar hanya dapat meningkatkan kemampuan berpikir secara terbatas, maka bahasa akan dapat lebih mengembangkan kemampuan ini. Dalam artian ini, berpikir dapat dibayangkan sebagai berinteraksi secara simbolik dengan diri sendiri.

Keempat, simbol meningkatkan kemampuan untuk menyelesaikan berbagai masalah. Binatang harus menggunakan trial and error, tetapi manusia

8 Ibnu Elmi dan Jefry T (2018) Interkoneksi Nilai-Nilai Huma Betang Kalimantan Tengah Dengan Pancasila. Jurna Studi Agama dan Masyarakat. ISSN. 1829-8257. Vol. 14 No. 2.

${ }^{9}$ George Ritzer dan DouglasJ Goodman (2003) Teori Sosiologi Modern. Jakarta: Kencana Media. Hal 292-293 
dapat memikirkan dengan menyimbolkan berbagai alternatif tindakan sebelum benar-benar melakukannya. Kemampuan ini mengurangi peluang berbuat kesalahan yang merugikan.

Kelima, simbol memungkinkan aktor mendahului waktu, ruang dan bahkan pribadi mereka sendiri. Melalui penggunaan simbol, aktor dapat membayangkan seperti apa kehidupan di masa lalu atau seperti apa kemungkinan hidup di masa depan. Lagipula, aktor dapat secara simbolik mendahului pribadi mereka sendiri dan membayangkan seperti apa kehidupan ini dilihat dari sudut pandang orang lain. Inilah konsep teoritisi interaksionisme simbolik yang terkenal: mengambil peran orang lain.

Keenam, simbol memungkinkan kita membayangkan realitas metafisik seperti surga dan neraka.

Ketujuh, dan paling umum, simbol memungkinkan orang menghindar dari diperbudak oleh lingkungan mereka. Mereka dapat lebih aktif ketimbang pasif, artinya mengatur sendiri mengenai apa yang akan mereka kerjakan.

Apabila fungsi simbol di atas dikaitkan dengan aksi dan interaksi, maka teoritisi interaksionisme simbolik memusatkan perhatian terutama pada dampak dari makna dan simbol terhadap tindakan dan interaksi manusia dalam bentuk prilaku lahiriah dan prilaku tersembunyi. Perilaku lahiriah adalah perilaku sebenarnya yang dilakukan oleh seseorang dalam interaksi sosialnya di lapangan. Sedangkan perilaku tersembunyi adalah proses berpikir yang melibatkan simbol dan arti. Beberapa perilaku lahiriah tidak melibatkan prilaku tersembunyi (perilaku karena kebiasaan atau tanggapan tanpa pikir terhaadap rangsangan eksternal $)^{10}$. Tetapi sebagian besar tindakan manusia melibatkan kedua jenis perilaku $\mathrm{itu}^{11}$. Perilaku tersembunyi menjadi sasaran perhatian utama teoritisi interaksionisme simbolik, sedangkan perilaku lahiriah menjadi sasaran perhatian utama teoritisi teori pertukaran atau penganut behaviorisme tradisonal pada umumnya.

\footnotetext{
${ }^{10}$ Abu Bakar HM. (2016) Huma betang dan Aktualisasi Nilai Kearifan Lokal dalam Budaya Dayak. Jurnal Humanika

${ }^{11}$ Ridwan Lubis (2005) Menelusuri Kearifan Lokal di Bumi Nusantara Catatan Perjalanan dan Hasil Dialog Pengembagan Wawasan Multikultural Antara pemuka Agama Pusat dan Daerah. Jakarta: Depag RI. Hal 13
} 
Simbol dan arti memberikan ciri-ciri khusus pada tindakan sosial manusia (yang melibatkan aktor tunggal) dan pada interaksi sosial manusia (yang melibatkan dua orang-orang aktor atau lebih yang terlibat dalam tidakan sosial timbal balik). Tindakan sosial adalah tindakan di mana individu bertindak dengan orang lain dalam pikiran. Dengan kata lain dalam melakukan tindakan seorang aktor mencoba menaksir pengaruhnya terhadap aktor lain yang terlibat. Meski mereka sering terlibat dalam perilaku tanpa pikir, prilaku berdasarkan kebiasaan, namun manusia mempunyai kapasitas untuk terlibat dalam tindakan sosial ${ }^{12}$.

Dalam proses interaksi sosial manusia secara simbolik mengkomunikasikan arti terhadap orang lain yang terlibat. Orang lain menafsirkan simbol komunikasi itu dan mengorientasikan tindakan balasan mereka berdasarkan penafsiran mereka. Dengan kata lain, dalam interaksi sosial para aktor telibat dalam proses saling mempengaruhi ${ }^{13}$. Dalam konteks historis masyarakat Dayak Kalimantan Tengah, Budaya Betang atau Huma Betang memiliki historis yang sangat besar pengaruhnya dalam merespon berbagai persoalan yang dihadapi. Konteks pemikiran ini dipahami dari peristiwa Rapat Damai Tumbang Anoi 1894 di Betang Tumbang Anoi yang dipimpin oleh Damang Batu. Peristiwa ini merupakan tonggak peradaban masyarakat Dayak dalam interaksi antar sesama masyarakat Dayak maupun dengan komunitas lainnya. Hal ini dijelaskan oleh Usop, KMA, sebagai kebangkitan budaya Dayak, maka inspirasi Rapat Damai Tumbang Anoi telah melahirkan perjuangan masyarakat Dayak mengangkat Utus Dayak (harakat dan martabat orang Dayak) dengan memperkuat adat, mengejar ketertinggalan, memberantas kebodohan, menembus keterisolasian dan keterasingan ${ }^{14}$. Refleksi dari Rapat Damai Tumbang Anoi tersebut menurut Usop, SR, adalah:

\footnotetext{
12 Ibid., hal 293-294

13 Deddy Mulyana (2010) Komuikasi Antarbudaya. Bandung: Remaja Rosdakarya. Hal 19

${ }^{14}$ KMA Usop dalam Sidik R Usop (2012) Budaya Betang Implementasi Pendidikan Karakter di Universitas Palangka Raya. Hal 45
} 
Tumbuhnya organisasi kemasyarakatan yang berjuang untuk mengangkat harkat dan martabat orang Dayak dari ketertinggalan, kebodohan dan keterasingan dari komunitas lainnya.

Menguatnya pemahaman Betang tempat penyelenggaraan peristiwa tersebut sebaagai simbol masyarakat multikultural yang sangat menghormati perbedaan-perbedaan yang secara nyata ada dalam kehidupan mereka.

Nilai Belom Bahadat, sebagai pedoman bagi kehidupan bersama, yaitu menghormati adat istiadat yang berlaku dalam wilayah adat yang bersangkutan.

Lahirnya lembaga adat yang berfungsi sebagai lembaga perdamaian adat dan menyelesaikan perkara yang terjadi antara masyarakat.

Berbagai kelembagaan kedayakan yang muncul pada masa Orde Baru antara lain Lembaga Musyawarah Masyarakat Dayak dan Daerah Kalimantan Tengah, Institut Dayakology di Kalimantan Barat, Persekutuan Dayak Kalimantan Timur dan Lembaga Musyarawarah Masyarakat Dayak Meratus di Kalimantan Selatan serta Borneo Research Council (BRC) yang melakukan kajian terhadap budaya Kalimantan ${ }^{15}$.

Berbagai telaah historis di atas memberikan gambaran yang kongkrit tentang kearifan lokal yang telah dibangun dan terus diperkuat kembali melalui berbagai kebijakan strategis, sehingga produk budaya yang diwariskan kepada generasi yang akan datang menjadi kebanggaan mereka, karena telah mampu menemukan jati diri sebagai suatu bangsa yang bermartabat.

Inspirasi yang dapat ditarik dari perspektif historis di atas adalah: terciptanya dinamika struktur kelembagaan adat dalam membangun perubahan, munculnya kesadaran kolektif msyarakat untuk memperkuat identitas dan jati diri sebagai bangsa yang berbudaya,dan membangun jaringan kerjasama bagi percepatan pembangunan kawasan regional Kalimantan dalam memperbesar kontribusinya terhadap pembangunan nasional.

Untuk memperjelas bagaimana proses revitalisasi nilai-nilai budaya Dayak Kalimantan Tengah dalam realitas sejarah, digambarkan sebagai berikut: ${ }^{16}$

\footnotetext{
${ }^{15}$ Ibid., Hal 47-48

${ }^{16}$ Ibid., Hal 48-49 
Tabel 1

Revitalisasi Kebudayaan Dayak Kalimantan Tengah

\begin{tabular}{|c|c|c|c|}
\hline $\begin{array}{l}\text { Kebudayaan } \\
\text { Dayak }\end{array}$ & $\begin{array}{c}\text { Pengetahuan } \\
\text { atau Nilai-Nilai }\end{array}$ & Makna & Refleksi \\
\hline Budaya Betang & $\begin{array}{l}\text { Integrasi dalam } \\
\text { kehidupan } \\
\text { pluralis }\end{array}$ & $\begin{array}{c}\text { Inspirasi } \\
\text { perjuangan } \\
\text { masyarakat } \\
\text { Dayak }\end{array}$ & $\begin{array}{l}\text { Perjuangan untuk mengangkat } \\
\text { harkat dan martabat warga Betang } \\
\text { menjadi tuan di negeri sendiri }\end{array}$ \\
\hline Pakat Dayak & $\begin{array}{l}\text { Kerjasama } \\
\text { toleransi dan } \\
\text { partisipasi }\end{array}$ & $\begin{array}{l}\text { Identitas } \\
\text { komunal }\end{array}$ & $\begin{array}{c}\text { Kebangkitan warga Dayak } \\
\text { menghadapi tantangan hidup yang } \\
\text { selama ini menghimpit mereka }\end{array}$ \\
\hline Utus & $\begin{array}{l}\text { Jati diri/ harga } \\
\text { diri }\end{array}$ & $\begin{array}{c}\text { Batas-batas } \\
\text { budaya (Cultural } \\
\text { boundaries) yang } \\
\text { tidak bisa } \\
\text { diganggu }\end{array}$ & $\begin{array}{c}\text { Kesejajaran harkat dan martabat } \\
\text { orang Dayak denegan komunitas } \\
\text { lainnya }\end{array}$ \\
\hline Pahewan & $\begin{array}{c}\text { Kelestarian } \\
\text { lingkungan alam }\end{array}$ & $\begin{array}{l}\text { Perlindungan } \\
\text { atau pencegahan } \\
\text { kerusakan alam }\end{array}$ & $\begin{array}{c}\text { Eksploitas sumber daya hutan } \\
\text { yang merugikan masyarakat }\end{array}$ \\
\hline Manakir Petak & $\begin{array}{l}\text { Berjuang untuk } \\
\text { mencapai } \\
\text { keberhasilan }\end{array}$ & $\begin{array}{l}\text { Perang melawan } \\
\text { ketidakdilan }\end{array}$ & $\begin{array}{c}\text { Perubahan terhadap struktur yang } \\
\text { telah lama membelenggu warga } \\
\text { Dayak }\end{array}$ \\
\hline Budaya Pantan & $\begin{array}{c}\text { Keterbukaan } \\
\text { terhadap } \\
\text { pendatang dari } \\
\text { luar } \\
\end{array}$ & $\begin{array}{c}\text { Semangat } \\
\text { egaliter dan tetap } \\
\text { mempertahankan } \\
\text { jati diri }\end{array}$ & $\begin{array}{l}\text { Konsekuensi dalam pergaulan } \\
\text { dalam masyarakat multikultur }\end{array}$ \\
\hline Isen Mulang & $\begin{array}{l}\text { Ketangguhan } \\
\text { dalam } \\
\text { menghadapi } \\
\text { tantangan alam }\end{array}$ & $\begin{array}{l}\text { Tindakan yang } \\
\text { selalu } \\
\text { berorientasi pada } \\
\text { prestasi }\end{array}$ & $\begin{array}{c}\text { Tantangan dalam menghadapi } \\
\text { persaingan di era global }\end{array}$ \\
\hline
\end{tabular}

\section{Bahasa dan Nilai-Nilai Kearifan dalam Simbol Budaya Lokal}

Untuk menghubungkan paparan di atas dengan kajian selanjutnya, maka nilai-nilai kearifan dan simbol budaya lokal akan selalu muncul dan ditemukan dalam hasil wawancara seperti penggunaan simbol bahasa dengan istilah-istilah Dayak, simbol budaya dengan filosofi Huma Betang, simbol Rumah Ibadah sebagai gambaran kerukunan, sebagai berikut ${ }^{17}$ :

Sidik Rahman Usop, seorang cendekiawan Muslim Indonesia dan Pemerhati masalah-masalah sosial di Kalimantan Tengah dan Dosen Universitas Palangka Raya, menjelaskan bahwa memaknai sikap keberagamaan masing-

${ }^{17}$ Sidik R Usop (2014) Cendekiwan Muslim Indonesia, Pengurus Forum Komunikasi Dayak Muslim dan Dosen Univrsitaspalangka Raya. Wawancara tanggal 26 Mei 2014. di Palangka Raya 
masing Tokoh Agama dilakukan melalu pemaknaan simbol budaya, sebagai perekat dalam kehidupan bermasyarakat, seperti:

Simbol Batang Garing sebagai falsafah hidup, yang menggambarkan keseimbangan hubungan: (1) manusia dengan sesama manusia; (2) hubungan manusia dengan alam semesta, dan (3) hubungan manusia dengan Sang Pencipta.

Simbol Budaya Betang, yang menggambarkan nilai filosofi: (1) masyarakat multikultural yang menghargai perbedaan; (2) kejujuran; (3) kebersamaan/toleransi; (4) kemandirian/otonomi; (5) kesetaraan sesama manusia; (6) persaudaraan; (7) kekeluargaan/ kekerabatan; (8) Hapakat Basara (musyawarah untuk mufakat).

Simbol Isen Mulang, yang menggambarkan nilai folosofi: (1) ketangguhan dan (2) orientasi pada prestasi /keberhasilan.

Simbol Harati, yang mengandung nilai: (1) kecerdasan (2) nilai keuletan.

Belom Bahadat, yang menggambarkan nilai filosofi: (1) tata krama dan sopan santun, hubungan antara yang tua dan muda, senior dan yunior dan menghargai profesionalitas; (2) memelihara moralitas (3) peduli kebersihan dan pelestarian lingkungan.

Pemaknaan simbol bahasa, sebagai media komunikasi antar Elit Agama dengan menggunakan bahasa Agama. Dalam tradisi yang berlaku di Kalimantan Tengah dan Palangka Raya khususnya, bahwa setiap pejabat atau tokoh masyarakat/agama yang menyampaikan sambutan pada setiap ada kegiatan baik tingkat daerah, regional maupun nasional selalu mengawali sambutannya dengan menyampaikan salam kerukunan yaitu: Islam, "Assalamu Alaikum Warahmatullahi wabarakatuh; Hindu, "Omswastyastu”; Kaharingan, "Tabe Salamat, Lingu Nalatai, Salam Sujud Karendem Malempang," Kristen, (Protestan dan Katolik), "Syelum"; Buddha, "Namo Buddhaya"; Konghucu, "Wei De Dong Tian"; Adat Dayak, "Adil Ka' Talino, Bacuramin Ka' Saruga, Basingat Ka'Jubata". Hal ini dimaksudkan bahwa sebagai umat beragama, selalu menyadari pentingnya membangun komunikasi dengan Tuhan YME, Allah SWT, dengan harapan selalu diberikan keselamatan, kedamaian dan kesejahteran dalam semua usaha yang dilakukan sekaligus sebagai wujud kearifan lokal, yakni selalu 
menghidupkan nilai budaya daerah sebagai bagian dari upaya mempertahankan dan memelihara nilai budaya bangsa serta mempertebal rasa nasionalisme.

Untuk mengetahui maksud dari masing-masing salam kerukunan penting dijelaskan sebagai berikut:

Agama Islam, "Assala>mu 'Alaikum wa Rahmatulla>hi wa Baraka>tuh." Artinya: selamat kepada kamu sekalian, semaga Allah melimpahkan Rahmat dan berkah-Nya, dijawab dengan $W a$ 'a>laikumussala $>m$ wa Rahmatulla $>h$ wa Baraka>tuh.

Agama Hindu, "Om Swatyastu." Artinya: semoga selalu dalam kebaikan lalu dijawab dengan Om Swatyastu diakhiri dengan Om Santhi, santhi, santhi om yang artinya damai di bumi, damai di akhirat, damai selalu.

Kaharingan, "Tabe salamat, lingui nalatai, salam sujud karendem malempang." Artinya: selamat bertemu dalam keadaan bahagia, dijawab dengan Sahiy, artinya terima kasih.

Agama Kristen (Protesten dan Katolik), "Syelum," dijawab dengan Syelum.

Agama Buddha, "Namo Buddhaya." Artinya: terpujilah Yang Buddha, dijawab dengan, “ Namo Buddhaya”.

Agama Konghucu, "We de dong Tyen." Artinya: hanya kebajikan Tuhan berkenan, dijawab dengan, "Xian You YI De." Artinya sungguh miliki satu kebajikan.

Adat Dayak, “Adil Ka'talino, Bacuramin Ka'saruga, Basingat Ka'jubata." Artinya: adil kepada manusia, bercermin ke surga, bernapas kepada Tuhan. Dijawab, "Harus." Artinya: sesuatu yang harus dilakukan. Maksudnya: dengan Rahmat Tuhan Yang Maha Kuasa dan berpedoman kepada ajaran agama/kepercayaan, bersikap adil kepada sesama manusia ${ }^{18}$.

Pemaknaan simbol Bahasa, sebagai media komunikasi dalam kehidupan bermasyarakat, seperti ungkapan:

\footnotetext{
${ }^{18}$ Baehaki (2014) Kepala Kantor Kemenag Kota Palangka Raya/Wakil Ketua PW NU Kalimantan Tengah. Wawancara tanggal 11 Mei 2014. di Palangka Raya 
"Penyang Hinje Simpei, paturuk humba tamburak", artinya: Memelihara kerukunan, keamanan dan interaksi sosial dalam kehidupan.

"Penyang ketum hinje simpei, patarung ketum humba tamburak, taketun belum panju-panjung, tatau sanang urah ngalawan, kilau bulan matan andau, tanggeran lewu maderah danum," artinya: Bersatulah kamu dengan seluruh kekuatan, dengan satu padumu, kamu akan hidup bahagia, seperti bulan, matahari dan bintang di langit sebagai contoh teladan.

“Amun ketun penyang pangangkarak simpei, te ketun akan gandang tatah lewu mandereh danum, amun patarung bahkuhas, akan gandang biwih rundang hampamantai tambun," artinya: Kalau terjadi perpecahan, engkau akan diejek dan dihina oleh bangsa lain, agar dunia ini damai, sejahtera hidup di dunia dan sempurna di dunia lain, maka berpeganglah kepada pedoman hidup yaitu agama .

"I Nyaho hai mamparijet tungkupa, kilat panjang mampanyo hai ruang," artinya: Guntur/suara agung membuka kuasanya, kilat panjang menggerakan ruang.

"Sansarena-rena naharukang lamiang bua garing belum, hanyang pating perang bahandang ije jadi bakandang aseng darah belu, basung gahung paninting aseng aluh hatampulu asan batu kuah tau malik handang, hangkahanya kantihen isen mules bantiasae," artinya: Hidup manusia telah memiliki pedoman, walaupun bertubi-tubi ditimpa cobaan dan godaan, ia bangkit tidak hilang hakekat hidupnya sebagai manusia yang bermartabat.

“Adil Katalino bacuramin kasaruga, basingat kajubata," artinya: Selamat dan sejahtera bagi kita semua dalam menjalani kehidupan.

Hal ini menggambarkan bahwa setiap manusia harus memiliki kepedulian atas keselamatan dan kesejahteraan orang lain, sehingga ungkapan ini selalu diucapkan ketika mengawali setiap pertemuan dalam forum-forum resmi pada tingkat lokal maupun regional ${ }^{19}$.

Berdasarkan deskripsi pandangan subyek dan uraian yang telah disajikan di atas, maka memaknai sikap keberagamaan Tokoh Agama dilakukan melalui:

\footnotetext{
${ }^{19}$ Lewis KDR (2014) Ketua Dewan Pertimbangan Majeli Besar Agama Hindu kaharingan. Wawancara tanggal 11 Mei 2014 di Palangka Raya 
Pemaknaan simbol budaya sebagai perekat dalam kehidupan masyarakat, meliputi: simbol Batang Garing yang menggambarkan kesimbangan hubungan antara manusia dengan manusia, manusia dengan alam dan manusia dengan sang Pencipta. Simbol Budaya Betang, yang menggambarkan nilai-nilai filosofi: masyarakat multikultural yang menghargai perbedaan, kejujuran, kebersamaan/toleransi, kemandirian, kesetaraan, persaudaraan, kekeluargaan; dan Hapakat Basara (musyawarah mufakat); dan simbol Isen Mulang, menggambarkan: ketangguhan, orientasi pada prestasi. Simbol Harati yang menggambarkan: kecerdasan, keuletan; simbol Belom Bahadat menggambarkan Tata Krama, sopan santun, menghargai profesionalisme dan memelihara moralitas.

Pemaknaan simbol Bahasa, sebagai media komunikasi dalam membangun interaksi antar Tokoh Agama dalam berbagai kegiatan keumatan, seperti mengucapkan salam adat dalam bahasa Dayak pada setiap pertemuan monumental yaitu: “Adil ka'talino, Bacuramin Ka'saruga, Basingatka'jubata dan Tabe salamat, lingui nalatai, salam sujud karendem malempang;

Pemaknaan Simbol Rumah Ibadah sebagai filosofi kerukunan, yakni letak beberapa mesjid dan gereja yang berada dalam satu komplek dan saling berdekatan, dan tidak pernah melahirkan konflik antar Tokoh Agama, tetapi justru melahirkan kebersamaan dan harmonisasi dalam menghargai perbedaan, seperti pada waktu Hari Raya Idul Fitri dan Idul Adha para pemuda gereja menjaga keamanan selama ibadah berlangsung, begitu juga sebaliknya ketika saudara-saudara yang beragama Nasrani melaksanakan ibadah, pemuda mesjid bertugas untuk menjaga keamanan selama berlangsung ibadah.

Memaknai secara arif melalui sikap saling menghormati perbedaan sebagai keniscayaan, menyadari kemajemukan sebagai fondasi kerukunan antar Tokoh Agama, sehingga melahirkan kebersamaan sebagai tujuan dan cita-cita bersama antar Tokoh Agama.

Proaktif membangun harmonisasi melalui dialog kemanusiaan dan dialog iman dan keterbukaan para Tokoh Agama untuk saling mengingatkan jika terjadi pelanggaran terhdap batas-batas yang harus dipelihara. 


\section{KESIMPULAN}

Secara umum bahwa pola interaksi sosial antar Tokoh Agama di Palangka Raya adalah pola interaksi "solidaritas integratif", hal tersebut ditandai dengan beberapa nilai perekat dalam simbol budaya lokal di Palangka Raya yaitu:

Nilai Belom Bahadat, yaitu nilai budaya yang selalu menjunjung adat. memiliki rasa kebersamaan dalam membangun solidaritas, keterbukaan dan ketulusan dalam melayani tamu sebagai wujud masyarakat plural, kemudian saling menghargai persatuan dan kesatuan serta perbedaan masing-masing agama, karena perbedaan merupakan sunnatullah dan keniscayaan yang tidak mungkin diabaikan. Semangat gotong royong, musyawarah dan kesetaraan sebagai wujud dari budaya huma betangyang menjadi budaya masyarakat Dayak.

Adil Ka'talino, yaitu menghargai keadilan dan kebenaran, membangun keseraian, keselarasan dan kesimbangan sebagai tradisi turun temurun yang telah diwariskan dari generasi terdahulu.

Nilai Belom Penyang Simpei, yaitu hidup damai dan sejahtera sebagai implementasi dari harmonisasi budaya Dayak.

Nilai spiritualitas Pancasila, sebagai simpul perekat semangat kebangsaan berdasarkan kearifan budaya lokal dan kekuatan integratif budaya nasional Pancasila, sehingga Kalimantan Tengah dan Palangka Raya dikenal dengan motto, “Bumi Tambun Bungai Bumi Pancasila, Bhinneka Tungggal Ika.” Namun disadari pula bahwa pada situasi tertentu kadang-kadang dimungkinkan terjadinya interaksi disintegrasi secara personal di kalangan masyarakat akar rumput, karena dilatarbelakangi oleh sejarah perkembangan dan pengmbangan agama Islam dan Kristen sebagai agama missi, sehingga menggambarkan terjadinya persaingan antara keduanya walaupun dalam konteks konflik laten. Dengan demikian maka menjadi tugas para Tokoh Agama untuk mengupayakan terwujudnya interaksi integratif, pada semua level kehidupan masyarakat. 


\section{DAFTAR PUSTAKA}

Abubakar, dkk, (2018) Elit Agama Dan Harmonisasi Sosial Di Palangka Raya. Jurnal Khazanah: Jurnal Studi Islam dan Humaniora P-ISSN 0215$\underline{837 X}$ and E-ISSN 2460-7606. $\quad$ Vol. $16 \quad$ No. 2 DOI: http://dx.doi.org/10.18592/khazanah.v16i2.2337

Abubakar. (2016) Huma Betang dan Aktualisasi Nilai Kearifan Lokal dalam Budaya Dayak. Jurnal Humanika. Vol 1. No 2.

Allport, GW dalam D Hendropuspito, O.C. (1994), Sosiologi Agama. Jakarta: Kanisius.

Arifin, Syamsul. (1996) Spritual dalam Peradaban Massa. Yogyakarta: Sipee

Arifin, Syamsul. (1996) Agama Konflik dan Interaksi Sosial. Yogyakarta: Pengalaman dari Desa Mojorejo (Laporan Penelitian S2)

Baehaki (2014) Kepala Kantor Kemenag Kota Palangka Raya/Wakil Ketua PW NU Kalimantan Tengah. Wawancara tanggal 11 Mei 2014. di Palangka Raya

Douglas, Goodman (2003) Teori Sosiologi Modern. Jakarta: Kencana Media

Elmi, Ibnu dan Jefry T (2018) Interkoneksi Nilai-Nilai Huma Betang Kalimantan Tengah Dengan Pancasila. Jurnal Studi Agama dan Masyarakat ISSN.

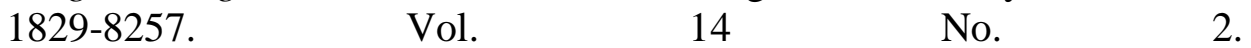
DOI: https://doi.org/10.23971/jsam.v14i2.928

Lewis KDR (2014) Ketua Dewan Pertimbangan Majeli Besar Agama Hindu kaharingan. Wawancara tanggal 11 Mei 2014 di Palangka Raya

Lubis, Ridwan. (2005) Menelusuri Kearifan Lokal di Bumi Nusantara Catatan Perjalanan dan Hasil Dialog Pengembagan Wawasan Multikultural Antara Pemuka Agama Pusat dan Daerah. Jakarta: Depag RI

Mulyana, Deddy. (2010) Komuikasi Antarbudaya. Bandung: Remaja Rosdakarya.

Naser, Haeder. (1997) Agama dan Krisis Manusia Modern. Yogyakarta: Pustaka Pelajar.

Ngalimun (2018) Komunikasi Antarbudaya. Yoyakarta: Pustaka Pelajar.

Ngalimun dan Makmur Harun (2020) Bahasa dan Komunikasi Perspektif Budaya. Yogyakarta: K-Media

Sidik R Usop (2012) Budaya Betang Implementasi Pendidikan Karakter di Universitas Palangka Raya. Makalah

Sidik R Usop (2014) Cendekiwan Muslim Indonesia, Pengurus Forum Komunikasi Dayak Muslim dan Dosen Univrsitaspalangka Raya. Wawancara tanggal 26 Mei 2014. di Palangka Raya

Tonnies Ferdinan dalam soerjono Soekanto (1997), Sosiologi. Jakarta: Raja Grafindo Persada. 